\section{Guidance to the applicability of the Global Lung Initiative spirometry reference equations for South African populations}

To the Editor: The lack of appropriate reference data for assessment of respiratory function in African populations and its implications for correct diagnosis and management of respiratory disease are longstanding concerns. The Global Lung Initiative $2012\left(\mathrm{GLI}_{2012}\right)$ has the largest data set that provides guidance for spirometry reference equations across all ages for diverse populations across the world. ${ }^{[1]}$ Until recently, the major limitation to its use in Africa was the lack of data from black African populations. A similar limitation applies to other currently used equations, and it is the reason for current recommendations for ethnic corrections, although the latter are not broadly validated, particularly in paediatric and adolescent populations. The only contribution of African population data to the GLI data set is from North Africa, where the ethnic background of the population was categorised as 'Caucasian' in the data set. The limitations of the recommendation from the North African population were also noted as being inappropriate compared with local previously derived Tunisian reference equations. ${ }^{[2]}$ The challenges associated with lack of data from healthy populations in Africa are linked to multiple factors, some of which are lack of access to resources, technical expertise and equipment to collect large data sets of healthy African populations. ${ }^{[3]}$

The South African Thoracic Society adult spirometry guidelines published in 2013 recommend that a correction factor of 0.9 for black and Asian individuals and 0.95 for individuals of mixed ethnicity be employed when European-based equations (e.g. European Coal and Steel Community predictions) are used. ${ }^{[4]}$ These recommendations were based on lack of local data at the time and the perceived inappropriateness of the GLI equations for adult black Africans. ${ }^{[5]}$

A previous systematic review of retrospective evidence from African populations had recommended the use of the GLI-African American equation in adults and children in sub-Saharan Africa, although data from West African populations showed a poor fit to all the reference equations. ${ }^{[6]}$ Prospective data on children in four other sub-Saharan countries have recommended the use of the GLIAfrican American equation for paediatric populations. ${ }^{[7,8]}$

Based on the findings of the retrospective African data set, a prospective study in $>3000$ South African (SA) adults and children of various ethnicities was performed to assess the appropriate GLI references that should be utilised in the SA context. ${ }^{[9]}$ Based on the results of this study, we would strongly recommend that for SA black African and mixed-ethnicity populations the GLI-'Other' reference equation should be utilised when performing spirometry. The GLI-White equation should be utilised for white South Africans, and the GLI-SE Asian equation for Indians. A critical finding of this study, which has been replicated in multiple studies, is that the forced expiratory volume in 1 second $\left(\mathrm{FEV}_{1}\right) /$ forced vital capacity (FVC) ratio is stable and is independent of the reference utilised, and can be relied on to diagnose airway obstruction in a goodquality test and using age-adjusted cut-offs for disease (Table 1).

While we are aware of the limitations of the recent SA study, which mainly included black Africans of Zulu and Xhosa descent, it represents a major step towards appropriate

Table 1. Reference equations and fit for South African populations

\begin{tabular}{llll}
\hline & $\begin{array}{l}\mathrm{FEV}_{1} z \text {-score, } \\
\text { mean }(\mathrm{SD})\end{array}$ & $\begin{array}{l}\mathrm{FVC} z \text {-score, } \\
\text { mean }(\mathrm{SD})\end{array}$ & $\begin{array}{l}\mathrm{FEV}_{\mathbf{1}} / \mathrm{FVC} z \text {-score, } \\
\text { mean }(\mathrm{SD})\end{array}$ \\
\hline Black African (GLI-'Other') & $0.13(1.28)$ & $0.13(1.32)$ & $-0.01(0.87)$ \\
Mixed ethnicity (GLI-'Other') & $0.22(1.44)$ & $0.24(1.56)$ & $-0.02(0.85)$ \\
Indian (GLI-SE Asian) & $0.18(1.03)$ & $-0.13(1.09)$ & $-0.1(0.93)$ \\
White (GLI-White) & $0.21(1.22)$ & $0.19(1.24)$ & $0.02(0.91)$
\end{tabular}

$\mathrm{GLI}=$ Global Lung Initiative; $\mathrm{FEV}_{1}=$ forced expiratory volume in 1 second; $\mathrm{FVC}=$ forced vital capacity; *A $z$-score of 0.0 would prediction values for the vast majority of South Africans, and an evidence-based implementation of the GLI reference values in southern Africa.

The change in the reference values suggested in this letter is endorsed by the South African Thoracic Society.

\section{Refiloe Masekela}

Department of Paediatrics and Child Health, School of Clinical Medicine, College of Health Sciences, University of KwaZulu-Natal,

Durban, South Africa

\section{Coenraad F N Koegelenberg}

Division of Pulmonology, Department of Medicine, Faculty of Health Sciences, Stellenbosch University and Tygerberg Academic Hospital, Cape Town, South Africa coeniefn@sun.ac.za

\section{Diane M Gray}

Department of Paediatrics and Child Health and MRC Unit on Child and Adolescent Health, Faculty of Health Sciences, University of Cape Town, South Africa

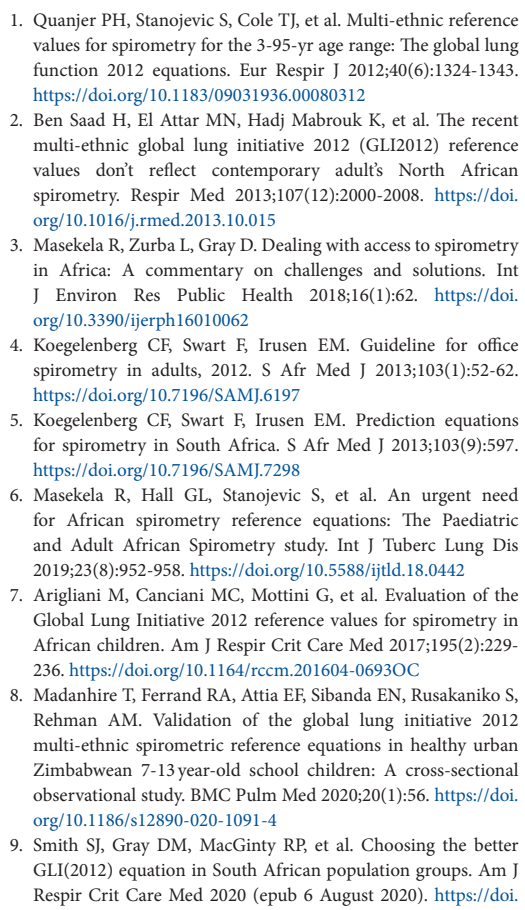

1. Quanjer PH, Stanojevic S, Cole TJ, et al. Multi-ethnic reference values for spirometry for the 3-95-yr age range: The global lung function 2012 equations. Eur Respir J 2012;40(6):1324-1343. https://doi.org/10.1183/09031936.00080312

2. Ben Saad H, El Attar MN, Hadj Mabrouk K, et al. The recent multi-ethnic global lung initiative 2012 (GLI2012) reference values don't reflect contemporary adult's North Africen spirometry. Respir Med 2013;107(12):2000-2008. https://doi spirometry. Respir Med 2013;107/
org/10.1016/j.rmed.2013.10.015

3. Masekela R, Zurba L, Gray D. Dealing with access to spirometry in Africa: A commentary on challenges and solutions. Int J Environ Res Public Health 2018;16(1):62. https://doi. org/10.3390/ijerph16010062

4. Koegelenberg CF, Swart F, Irusen EM. Guideline for office spirometry in adults, 2012. S Afr Med J 2013;103(1):52-62. https://doi.org/10.7196/SAMJ.6197

5. Koegelenberg CF, Swart F, Irusen EM. Prediction equations for spirometry in South Africa. S Afr Med J 2013;103(9):597. https://doi.org/10.7196/SAMJ.7298

6. Masekela R, Hall GL Stanojevic S, et al. An urgent need 6. Masekela R, Hall GL, Stanojevic S, et al. An urgent need
for African spirometry reference equations: The Paediatric and Adult African Spirometry study. Int J Tuberc Lung Dis 2019;23(8):952-958. https://doi.org/10.5588/ijtld.18.0442

7. Arigliani M, Canciani MC, Mottini G, et al. Evaluation of the Global Lung Initiative 2012 reference values for spirometry in African children. Am J Respir Crit Care Med 2017;195(2):229236. https://doi.org/10.1164/rccm.201604-0693OC

8. Madanhire T, Ferrand RA, Attia EF, Sibanda EN, Rusakaniko S, Rehman AM. Validation of the global lung initiative 2012 Rehman AM. Nalkation of the global hung initiate 2012 multi-ethic spirometric reference equations in healthy urban Zimberion observational study. BMC Pulm Med 2020;20(1):56. https://doi org/10.1186/s12890-020-1091-4

9. Smith SJ, Gray DM, MacGinty RP, et al. Choosing the bette GLI(2012) equation in South African population groups. Am Respir Crit Care Med 2020 (epub 6 August 2020). https://doi. org $/ 10.1164 / \mathrm{rccm} .202005-2085 \mathrm{LE}$

S Afr Med J 2021;111(2):97.

https://doi.org/10.7196/SAMJ.2021.v111i2.15439 